\title{
The Feature Selection Methodology (FSM): an approach for automotive companies to face a new paradigm in the Front End of Innovation
}

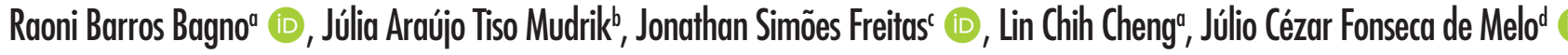 \\ - Departamento de Engenharia de Produção, Universidade Federal de Minas Gerais - UFMG, Belo Horizonte, MG, Brasil

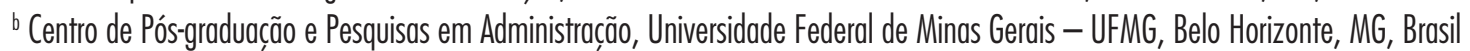 \\ ' Departamento de Ciências Administrativas, Universidade Federal de Minas Gerais - UFMG, Belo Horizonte, MG, Brasil \\ d Programa de Pós-graduação em Engenharia de Producçoo, Universidade de São Paulo - USP, São Paulo, SP, Brasil \\ e-mails: raonibagno@dep.ufmg.br, juliatiso@gmail.com, jonathans@face.ufmg.br, lincheng@dep.ufmg.br, juliocfmelo@gmail.com
}

\begin{abstract}
Feature development is about conceiving a set of functionalities prior to the products that embody them. Established automotive companies have numerous features in their portfolios, so, notwithstanding the challenge of creating new features, this study focused on the following problem that emerges in the Front End of Innovation of these companies: from the portfolio of available features, which ones to select for each new product specification? As a response, we propose the Feature Selection Methodology (FSM), designed over a 7-month action-research program conducted along with a global automotive company. Finally, general implications of FSM and Featuredriven development are discussed.
\end{abstract}

Keywords: feature-driven development, Front End of Innovation, innovation management, product development, automotive industry, portfolio management.

\section{Introduction}

The management of product innovations has occupied a central position in academia and business practices in the last decades. Innovative products are typically associated with high market and technological uncertainties and complexity (Holahan et al., 2014). In cases for which traditional managerial models tend to be poorly supportive (Katz, 2011), previous efforts oriented to reduce uncertainties may be performed before initiating the formal development process (Moenaert et al., 1995). The Front End of Innovation (FEI) corresponds to the earliest phase of the New Product Development (NPD) process (Reid \& De Brentani, 2004) and includes important activities such as product strategy formulation and communication, opportunity identification and assessment, idea generation, product definition, project planning and evaluation, and executive reviews (Khurana \& Rosenthal, 1998; Murphy \& Kumar, 1997).

Despite the progress that has been made in theoretical and empirical studies, the challenges to manage the frontend are still hard to handle. Also, methods and tools to deal with such challenges tend to be highly dependent on the specificities of the organization and its environment (Kim \& Wilemon, 2002; Oliveira et al., 2011). Therefore, many authors defend that organizations need to develop proper FEI processes and practices, which could fit to specific situations in the industry (Donaldson, 2001; Kim \& Wilemon, 2002; Oliveira et al., 2011).

An emerging paradigm in automotive NPD that tends to dramatically change processes and practices in FEI phase is the feature-driven development. In this context, a feature is defined as an "[...] identifiable aspect of the total offering that a critical reference group perceives and evaluates as an 'extra' to a known standard among comparable products" (Thölke et al., 2001, p. 4). For cars, examples of features could be a $4 \times 4$ traction, a retractable seat, a special function of an automatic gearbox, or even an integrated GPS. Featuredriven development represents one step back, more in-depth level in product conceptualization and, especially in the last years, the design and implementation of new features has turned into a very attractive strategy to allow customers to perceive benefit and differentiation of the products (Maniak et al., 2014). The adoption of a feature-driven approach is also providential for the automotive sector in the face of some important technological breakthroughs that have been reaching this industry such as the connected and autonomous car (Morris et al., 2018; Nikitas et al., 2019), the scale up of hybrid and electric vehicles (Chávez \& Lara, 2016) and the increasing application of modular 
architectures (Antonio et al., 2009; Persson \& Åhlström, 2013).

Therefore, besides the management of a product portfolio (in the sense used by Cooper et al., 1997), firms start to face the challenges of managing a feature portfolio. Noteworthy that components and/or subsystems associated with a given feature developed for a singular vehicle model or platform are not likely to be technically compatible with other applications (i.e. the physical parts or even software will rarely be interchangeable in practice). Even though, knowledge base and expertise, lessons learned (from the project development endeavours and from the field), experimental engineering and prototyping capabilities, supplier development, among other related elements, become resources available for the development projects of novel applications.

All these combined elements challenge the feature development perspective in automotive industry and carries relevant questions to be answered in FEI phase: e.g. what features should be developed and, from those features available in the current global portfolio, which ones should be selected for a new product. This study focuses on this second problem, from which the following research question was formulated: from the portfolio of available features of an automotive group, which ones to select for each new product specification?

To answer this question, we conducted an actionresearch program together with a subsidiary of a global car manufacturer company that lasted 7 months. As a result, the Feature Selection Methodology - FSM was proposed for the partner company. The FSM seeks to integrate several available information from both internal and external environments and intends to guide feature selection under a more effective way while offering an adequate balance between data-processing and collaborative work to boost better management insights. Finally, the implementation aspects and other organizational outcomes of the adoption of FSM are discussed.

\section{Theoretical background}

\subsection{The Front End of Innovation (FEl)}

Smith \& Reinertsen (1991) propose that the innovation process could be divided in three macro-phases: the Fuzzy Front End, product development and commercialization. Actually, in the last two decades a considerable research effort has been done to improve the FEI of the innovation process (Mendes \& Oliveira, 2015). According to some authors, FEI represents a great opportunity for reducing development time and resources (Khurana \& Rosenthal, 1998) and can decisively contribute to the success of a new product (Cooper, 1988). The FEI is often called the Fuzzy Front-End or even the predevelopment phase of the NPD process. For Khurana \& Rosenthal (1998) it includes product strategy formulation and communication, opportunity identification and assessment, idea generation, product definition, project planning, and early executive reviews. Murphy \& Kumar (1997) define FEI as consisting of idea generation, product definition, and project evaluation. They empirically found that firms undertake FEI's activities to create a clear product definition prior to the development and that the most important objective is to understand project requirements.

Kim \& Wilemon (2002) highlight the importance of the successful selection of the right opportunity. Also, the authors argue for the mission of the FEI in clearly defining a product concept during the FEI phase, since activities in the development phase (NPD) highly depend on these definitions. The product concept is defined by Khurana \& Rosenthal (1997) as the preliminary identification of customer needs, market segments, competitive situations, business prospects, and alignment with existing business and technology plans. Notwithstanding, they consider that product conceptualization is unexpectedly difficult and that most companies fail to generate clear product definitions.

In general, literature on FEI is criticized for offering just very generic models, which makes difficult for organizations to get clear prescriptions from them. There is an ongoing discussion as to whether or not the FEI process should or not be formalized in organizations and in what extent. Poskela \& Martinsuo (2009) examines the use of management control in the FEI and highlight that despite the phase's need for freedom and creativity in view of its uncertain context, some control is necessary to ensure the effective use of resources and the achievement of the company's long-term objectives. Koen et al. (2001) affirms that, at least in part, a new product success depends on a formalized front-end process. Despite that, it is noteworthy to consider that companies should not adopt the same frontend solution and that FEI is too critical and complex to be managed just by procedural and standardized processes. In this sense, firms need to be able to develop proper FEI processes and practices (Donaldson, 2001; Khurana \& Rosenthal, 1997; Kim \& Wilemon, 2002; Nobelius \& Trygg, 2002; Oliveira et al., 2011) that adequately considers their singular context and characteristics - e.g. company size, decision-making style, operating culture, and frequency of new product introduction (Khurana \& Rosenthal, 1997).

Some researchers recognize the difficult challenge of managing the FEI process and have presented proposals to add more structure to it. For example, Koen et al. (2001) propose a theoretical model to provide a common language and insights for FEI activities. Kim \& Wilemon (2002) suggest several strategies to help managing FEI activities and to assure the focus on their main objectives. These authors emphasize the need of an information system 
to support the efforts and the formalization of a holistic and efficient FEI process. By turn, Oliveira et al. (2011) investigated front-end attributes that need to be customized according to different degrees of product innovation to allow proper levels of structure and flexibility (Figure 1). They concluded that the development activities are strongly marked by information gathering efforts to reduce uncertainties and the decision criteria are among the central concerns to achieve this mission.

Recognizing the limitations of classic front end approaches, Markham \& Mugge (2015) and Katz (2011) affirm that the challenges raised by the "back end" (e.g. diffusion, commercialization) should be properly considered and managed. Thus, adjacent processes of ideation and evaluation need to tie well with other skunk work fronts like market intelligence and new business creation by means of more operational structures, guiding the transition from idea to formal product development (Markham \& Lee, 2013; Markham \& Mugge, 2015).

As a partial summary, from the literature discussed in this section, we can identify some important principles to take into account when designing methodological approaches for FEI such as: the use of common language in the process; the establishment of clear objectives to achieve; a proper balance between structure/objectivity and flexibility/ managerial insights for the activities in the face of the high uncertainty that characterizes the FEI phase; a strong focus on information gathering and analysing, considering diverse information sources.

\subsection{The automotive industry and the feature-driven approach}

The automotive is a mature industry in which most companies produce technically complex products and systems intended for high-volume applications (Elverum \& Welo, 2015). Especially in the last years, the proliferation of new products in increasingly saturated markets (Maniak et al., 2014), among other variables, have been intensifying the focus of the automotive companies on more innovative features, aiming to differentiate their products from those of the competitors (Backman et al., 2007).

Even though NPD-related processes are well implemented in most automotive companies, the early efforts associated with topics like pre-competitive research, product and market conceptualizations, technology development and others remain as tricky challenges for managers. For instance, Langner \& Seidel (2009) analyzed two automotive companies in developing new concepts of convertible roofs leaning on an approach of supplier competition during FEI. The authors underline the intense knowledge sharing that occurs and the bold hurdles associated with collaboration efforts in these early phases. In another study, Högman \& Johannesson (2013) investigated six established companies that applied stage-gate-like systems in technology development settings (among them, two automotive system architects/integrators). Although the study concludes that, in general, the companies did well with their models, higher levels of uncertainties and the need for continuous experimentation (normally strongly based on the use of prototypes as highlighted in Elverum \& Welo's (2015) study) required relevant adaptations and a much more flexible approach than those normally accepted in traditional NPD. This example reinforces the need for a balance between structure and flexibility in FEI endeavors, especially in sectors like automotive that deal with complexstructured products, higher levels of organizational formality and in which technology plays key roles.

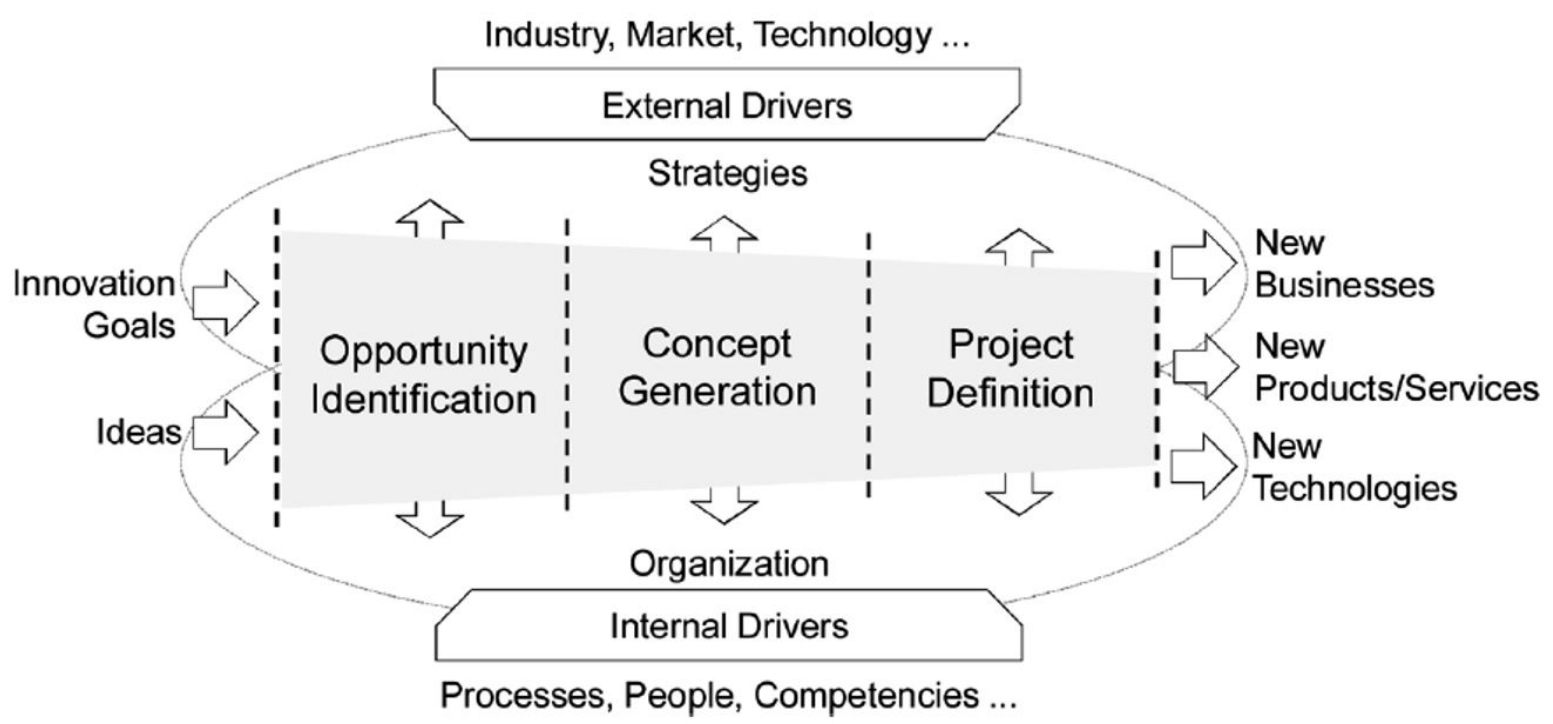

Figure 1. A conceptual framework of front-end attributes. Source: Oliveira et al. (2011). 
Adapting the definition proposed by Thölke et al. (2001), to the present context, a feature is an identifiable aspect of the product that represents a particular function (or value) for an identifiable customer profile. Therefore, the term is best associated with product added values/functionalities and not to interchangeable parts among products. In fact, a managerial approach for NPD that emphasizes new features instead of new whole products has potential to considerably impact on the conventional NPD and also brings the importance of the pre-development efforts to the forefront. Due to this reason, the development and evaluation of features, and the decisions regarding which features to consider in a new product specification become key issues for FEI in current automotive context.

The Front End of feature development is about conceiving technological solutions and functional concepts/ prototypes for a pilot product. The effective implementation of new features on marketable final products normally demands, in a more or less extent, relevant efforts in the development phase for each new product to which a feature come to be specified. Maniak et al. (2014) argue that a feature must be innovative in at least one of three possible dimensions: (i) it must offer a clear performance improvement; (ii) a substantial price reduction for a given attribute with equivalent performance; (iii) or a new, original attribute.

General examples of features in the definition here proposed could be a $4 \times 4$ traction, a retractable seat, a special function of an automatic gearbox, or even an integrated GPS. Albeit the concept itself is not associated with any particular technology field, the recent advances of Digital technologies for many purposes and their continuous integration to several vehicle platforms (Morris et al., 2018) have a central role in fostering feature development approaches in the automakers. Consequently, a featuredriven approach should impact the current organizational competences, spilling over to architectural choices, functional requirements, and established routines across different departments, thus disrupting traditional product templates (Maniak et al., 2014).

Feature-driven development represents one step back, more in-depth level in product conceptualization is intensely about conceptual and user-experience thinking. Kim et al. (2018) argue for "approaches that are grounded in the creation of customer experiences, and which drive the choices of features, functionality, and technology". Large-sized companies in the automotive context with their several product lines tends to present a lengthy list of features (developed and under development), which makes it propitious to manage as a portfolio. However, Lagerström et al. (2017) alert that that "features are heavily dependent on each other in a complex network, thus they should not be treated as isolated islands", which bring special challenges in managing such a portfolio in order to yield complete product specifications in the upper level.

\section{Research method}

This study was performed in a 7-month action-research (AR) program (Coughlan \& Coghlan, 2002; Eden \& Huxham, 1996). AR was applied firstly, because the study was motivated by a managerial real-world problem related to feature selection and to the specification of new vehicles. Secondly, because an academic team couldn't develop a methodology to properly tackle this kind of problem without the direct cooperation and involvement with the company team, who best know its organization and, ultimately, is the first users of the managerial knowledge built.

As a research methodology, AR aims both at taking action and creating knowledge about action (Coughlan \& Coghlan, 2002). It requires cooperation between members of an organization and researchers that use a scientific approach to study the resolution of important social or organizational problems in an interactive way (Eden \& Huxham, 1996). In this sense, AR focuses on research in action, rather than research about action (Coughlan \& Coghlan, 2002) and comprises three steps: (i) a pre-step - to understand context and purpose; (ii) six main steps - to gather, feedback and analyze data, and to plan, implement and evaluate action; (iii) a meta-step to monitor each of the six main steps and the learning process. By its nature, AR intervention is particular and situational. But the results make the research meaningful to other contexts.

The 7-month AR program was held between a large multinational automotive manufacturer and a research group of the production-engineering department of the Federal University of Minas Gerais (NTQI/UFMG - Brazil). The company team was formed by both managers and technicians of Feature Planning area, in Product Planning board. Product Engineering and Marketing Research areas were also involved during data collection and/or specific steps and Feature Planning \& Innovation top manager got involved in evaluation points whenever needed (see Table 1). Throughout this article we will refer to "company team" and "academic team" to individualize these two groups and we will use "research team" to make reference to the whole group of people that worked together in ARProgram (i.e. research team comprises both academic and company teams). We also use "Feature Planning team", "NPD team", etc. when convenient to refer to people and functions on company's structure (not necessarily in the context of AR-Program).

The main input data for the work was the global portfolio of features, which included features then applied in car models around the world and others in development stage. The features are categorized into general functions according to its description and benefits (e.g. The feature "Ambient 
Table 1. Research team.

\begin{tabular}{|c|c|c|}
\hline \multirow{15}{*}{$\begin{array}{l}\text { Research } \\
\text { team }\end{array}$} & Subteams & Participation \\
\hline & \multicolumn{2}{|c|}{ Company team } \\
\hline & Feature planning analyst & Entire program \\
\hline & Feature planning \& innovation coordinator & Entire program \\
\hline & Feature planning \& innovation manager & Entire program \\
\hline & Feature planning \& innovation director & Evaluation points \\
\hline & Market research analyst & $\begin{array}{l}\text { Market data collection, data processing, support in computational } \\
\text { tool prototype and tests }\end{array}$ \\
\hline & Product engineering analysts (7) & $\begin{array}{l}\text { FSM design: feature scoring (cost, investment development time), } \\
\text { support on FSM simulation/tests, final training sections }\end{array}$ \\
\hline & Business intelligence analysts (2) & $\begin{array}{l}\text { Support in computational tool prototype and tests, final training } \\
\text { sections }\end{array}$ \\
\hline & \multicolumn{2}{|r|}{ Academic team } \\
\hline & Industrial Engineering undergraduate students (5) & Entire program \\
\hline & Business and Administration master student & Entire program \\
\hline & Product Development and Innovation assistant professor & Entire program \\
\hline & Strategy and Methodology assistant professor & $\begin{array}{l}\text { AR-Program methodological approach, evaluation points, general } \\
\text { support in FSM and computational tool designs }\end{array}$ \\
\hline & Product Development and Innovation senior professor & Evaluation points \\
\hline
\end{tabular}

lighting with colour personalization" is categorized into "Increase visual differentiation" function; the feature " 1 st Row Charge Only USB Port" is categorized into "Increase entertainment" function). Due to strategic importance and confidentiality of the portfolio, the company team previously prepared a codified, synthetic and static portfolio, based on the real one, which was used during the most part of the work. The real list was defined and continually updated by Feature Planning areas from all global units.

The study followed 7 macro-steps presented in Figure 2, which also shows the main questions to be answered in each stage. A research diary and constant collective reflection were maintained to keep track of the learning process. Following Balogun et al.'s (2003) arguments in the strategizing field, we considered that "large, multinational, and highly diversified organizational settings require complimentary methods, providing more breadth and flexibility", So, all the endeavour was made seeking a collaborative research process from beginning to end (c.f. Balogun et al., 2003).

Firstly, the company team, the organizational areas that should be involved (e.g. in data collection) and people profile were defined. The aim was to develop an understanding of the context in which the AR program would be conducted and to define who should be evolved and why. This was a crucial activity for AR program, as its collaborative approach was based on the assumption that clients know their organization, know what works best and, ultimately, would be the ones to implement the resultant knowledge (Coughlan \& Coghlan, 2002). Secondly, the feature portfolio was formatted, codified and studied in order to understand the features characteristics and their current applications. The academic team studied the features' descriptions and analysed their application on car models around the world and their maturity (available or in development).

The third macro-step was the definition of managerial questions that should be answered to ensure better decisions in choosing features for a new product specification. Also, the definition of relevant data sources and their nature (e.g. Market, strategy, existing applications, etc.) was made. The fourth macro-step consisted of discussions, tests and definition of forms of data gathering, adjustment and processing. The contact made with different areas of the organization, especially Product Engineering and Market Research, was crucial to define how to gather data, and, once obtained, to define how to build a single platform for analysis - an information system - which could be continually updated over time. Meanwhile, the development of a supporting computational tool has started.

The fifth step was the design of the Feature Selection Methodology - FSM, which consisted of a logical process of data analysis and processing in accordance with the managerial questions defined. In this sense, the computational tool was refined to better support data processing, visualization and to automatize some analyses. The sixth step comprised the simulations and tests of the feature selection methodology and of its computational tool in the face of some demands for product specifications. This effort was first made with simulated/hypothetical vehicles and then with real products under pre-development phase (conducted only by the company team) after the portfolio data had been updated with no-coded features. 
Finally, detailed documentation of the methodology and of the computational tool were developed to ensure their correct use in a regular basis and their diffusion around the company. As expected in AR programs, the intervention was continuously built according to the results of the actions taken, information gathered and the learning process. In this sense, there were loops between the seven steps, represented in Figure 2. The entire research process was consciously conducted collaboratively with the company through weekly communication between researchers and company members, as well as monthly joint coordination and planning meetings. The program stakeholders periodically validated partial results in order to consolidate the milestones achieved. A great amount of presentations, minutes of meetings, e-mails and general annotations comprises the data used to base the discussions and implications proposed in section 5 .

\section{Results}

The AR program resulted in a 4-stage methodology the Feature Selection Methodology (FSM - Figure 3). This methodology seeks to integrate several information from both internal and external environments, and its output is the set of features to be included in the specification of a new car model and/or the identification of gaps to be filled by new feature development (i.e. when poor list of features returns from screening and scoring efforts). The FSM approaches the challenge of feature selection through a logical process of data gathering and analysing, helping to reduce the inherent uncertainties and the part of the subjective character of the decision taking at this phase. Also, it intends to guide the general Feature Planning team's activities and interfaces with other company's areas. An additional result of the AR program is a computational tool that processes and organizes all data gathered. Also, this tool adopts visual forms such as iterative graphics and tables in order to allow a friendly and effective use. This tool also allows data updating in the face of the frequent environmental changes (for instance, market research data used during stages 1 and 2 were updated each three months).

The FSM starts from the definition of a particular product model (i.e. a car or vehicle platform, but it is more accurate for single models), to which a feature specification template must be defined. The first three stages focus on features function selection. To do this, strategy, market and technology data are analysed as the main types of input data. Considering the macro process of innovation (i.e. FEI $+\mathrm{NPD}$, including diffusion), FSM is designed to support the Front End phase, especially in the product concept definition. Its general outcomes enter to NPD execution (i.e. list of features to be included in a new vehicle specification) and to the on-going product and portfolio strategy formulation (i.e. gaps for new features) (Figure 4). Following, the FSM stages are detailed.

\section{Stage 1: market diagnosis}

After deciding which car model requires a specification template, the first stage of FSM consists on a market diagnosis of overall customer's satisfaction in different feature's functions. The firm's relative position compared to its competitors is then identified (Leader, Above Average, Average, Below Average). When the company is working on a completely new product, an old similar model in terms of market niche (or even well-known competitors) can be used for the first analysis.

Two market survey reports were provided by Marketing area in order to allow inferences about customer satisfaction levels. Both surveys come from a consortium held in

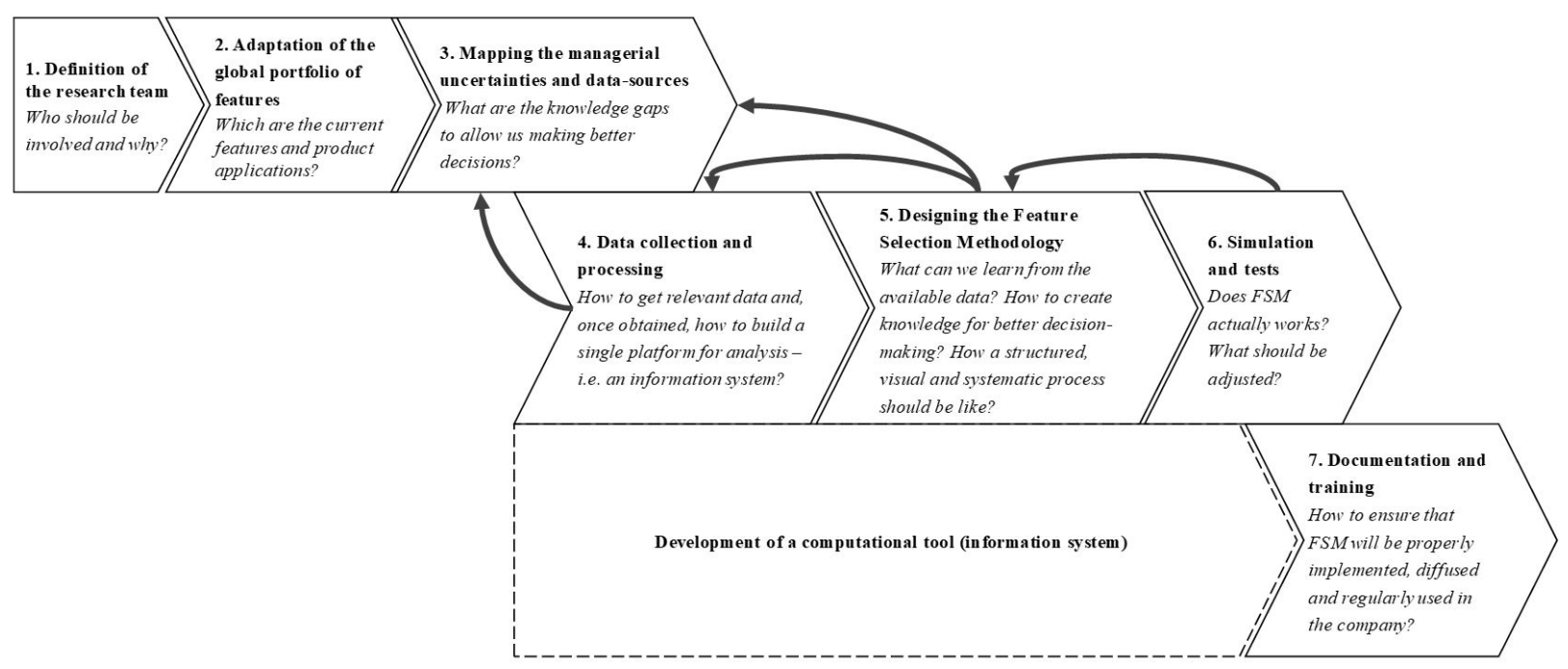

Figure 2. Research program steps. 


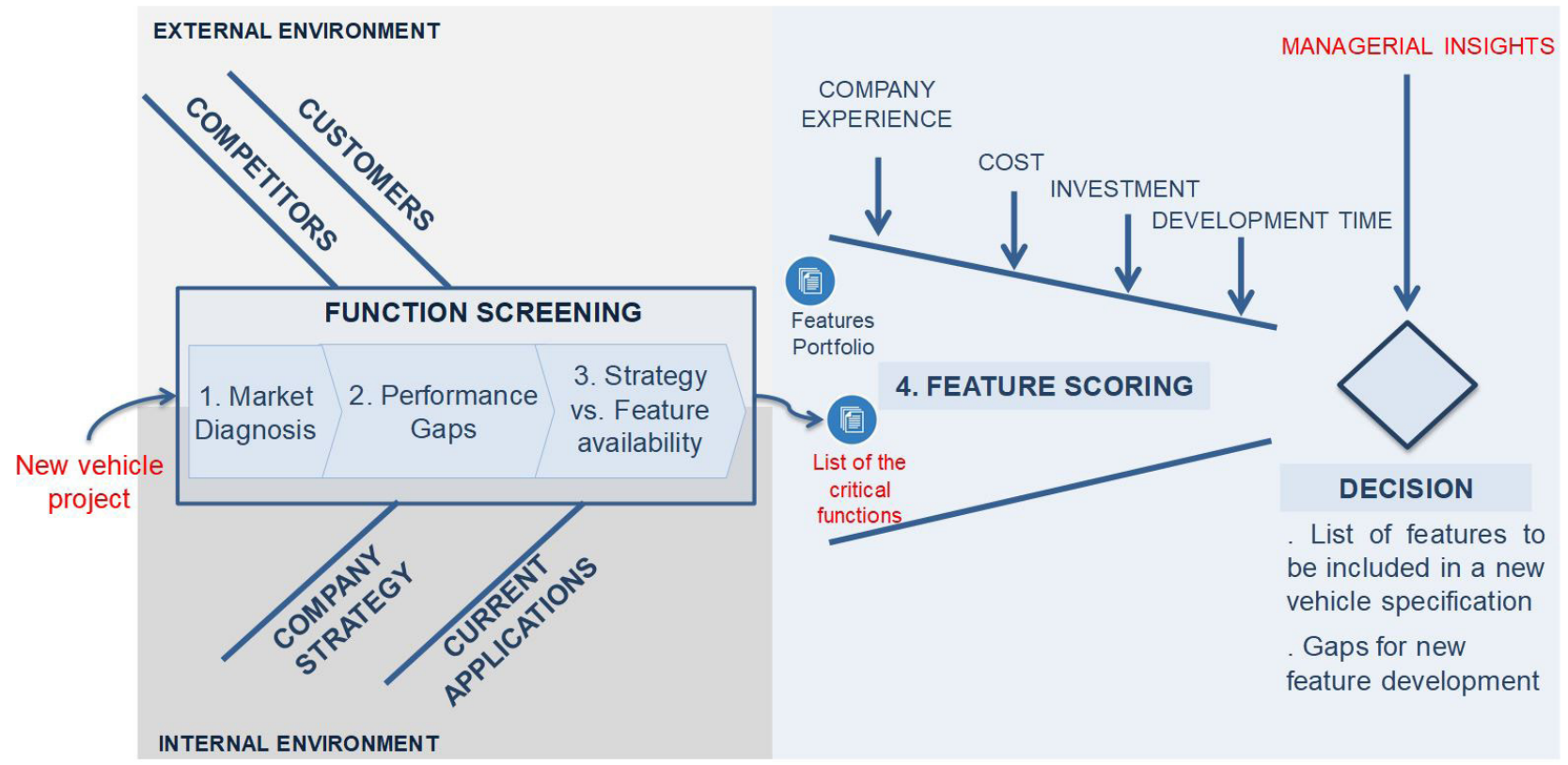

Figure 3. General view of FSM.

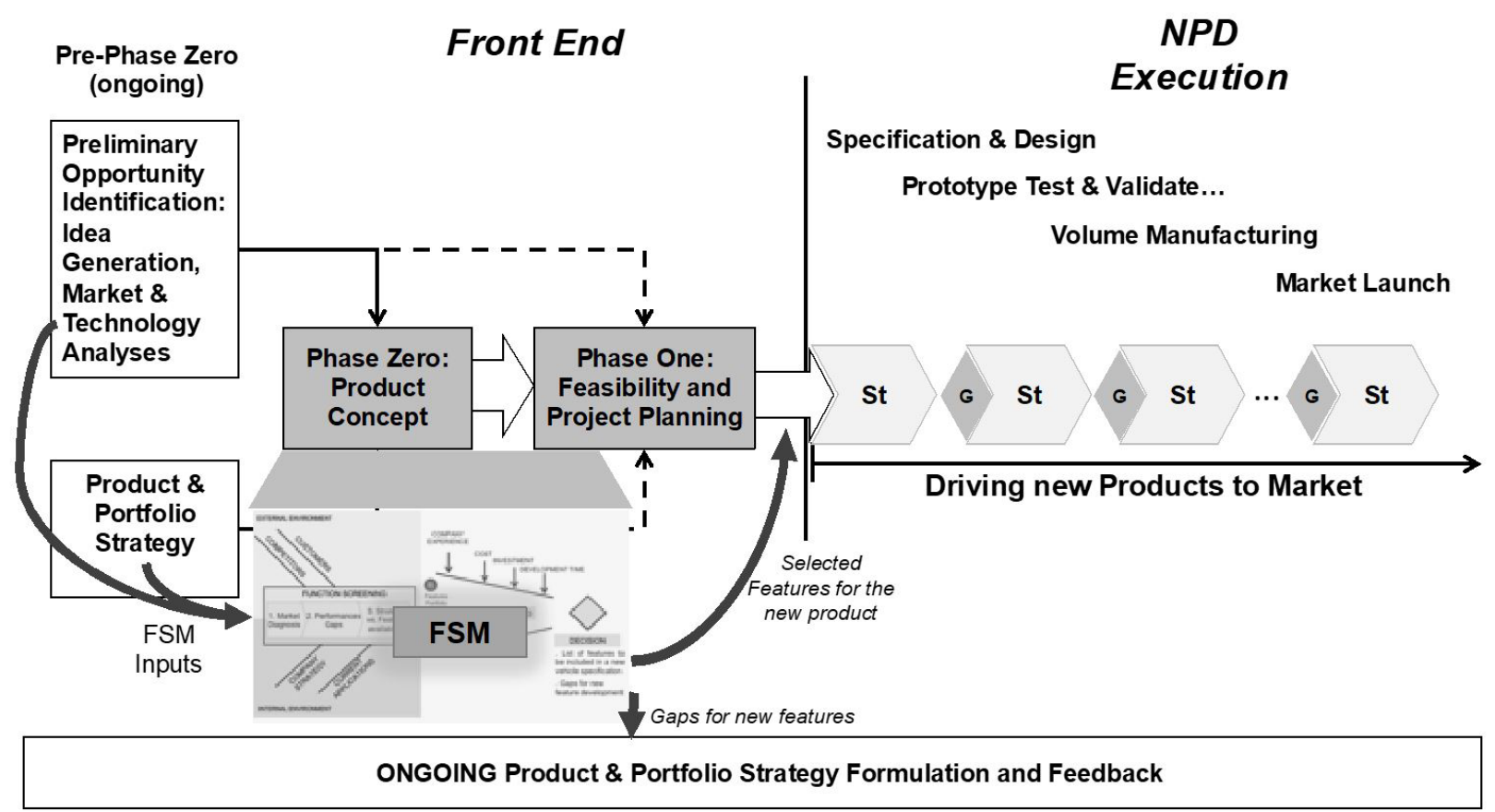

Figure 4. FSM in the New Product Development process.

partnership with other manufacturers and new data is available every three months. These reports were taken as secondary data sources, since they were not built for the same purposes as ours - i.e. the structure of each question was made to seek understanding of customer satisfaction with the vehicle as a whole, not to forecast customer desires about new features to include. This demanded us to interpret the research questions and correlate each one with feature's functions, making a few adjustments on the resultant data when needed. To identify the relative position of the manufacturer' brand against others, it was also necessary to define the current competitors of the niche in the analysis.

Figure 5 shows an example of the analysis made at this stage, comparing the current performance in customer satisfaction of the partner company's brand to that of its competitors for each feature function. 


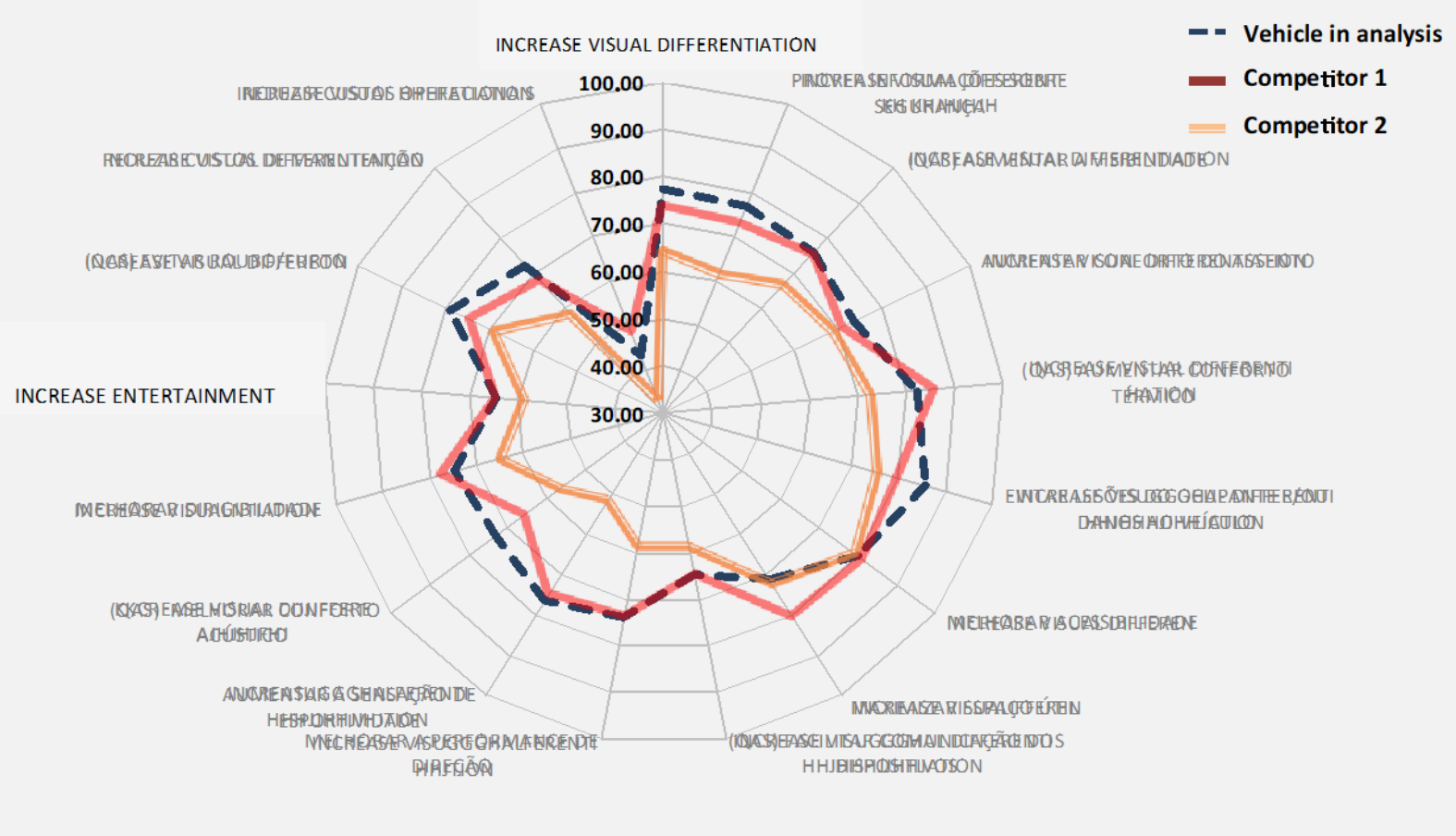

Figure 5. Radar chart - Customer's Satisfaction (note: some feature functions were intentionally hidden due to non-disclosure requirements).

\section{Stage 2: performance gaps}

The second stage adds information about product strategy to the analysis. For each function, the brand's real position is compared with the firm's product strategy. Such a strategy was defined in the terms of the scale - Leader, Above Average, Average, Below Average - for each feature function. In the computational tool, functions with lowerthan-desired performance are highlighted.

Stage 3: strategy vs. feature availability

At the third stage the product strategy and the product's relative performance in each function are used to analyse the available features in the current global portfolio. Not just the number of features available for critical functions is considered, but also the product's total cost in features. We recommend a set of managerial questions to nurture the analyses at this point (e.g. for the current scenario of this product, would there be a function not covered by any feature, but such a function seems to be important to the product strategy and/or presents lower satisfaction scores than the main competitors? Would there be any function in which current product presents high performance, but such a function is less important for the product strategy and/or is it associated with higher costs than other ones applied in this niche? Is it possible to reduce this total cost and/or would be preferable to redistribute it to other functions that emerge as critical?)
These first three stages intend to prioritize the proper set of functions for the best market performance of the concerned product.

\section{Stage 4: feature scoring}

The fourth stage aims at ordering features from previously screened functions according to some criteria such as similarity to current local applications, feature cost (per unit) and the forecasted development time/cost for making the feature available. A detailed database should be raised with the support of other areas of the company (e.g. Product Engineering), especially to understand complementary characteristics of features, based on engineering criteria. During this stage, the database is ordered and filtered according to the results of previous stages. Also, the development strategy of the concerned product helps to take inclusion/exclusion decisions (e.g. features with longer development times than required are excluded). The result is an ordered list of features that best meet the requirements of the development project and of the product itself. These features represent the most likely ones to be included in the product specification. This database with the complementary characteristics of the features (e.g. cost per unit and development time/cost) is essential for a refined final decision, once the FSM clearly consider at this stage the formal product target cost and development budget. 


\section{Decision}

The ordered list, its subjacent criteria and the visual maps generated along the previous analysis constitute, in an integrated form, the formatted instrument to guide the managerial decision on what features to include in each product specification. Some complementary graphics and other visual analyses are propitious to be included in the product briefing as the formal document delivered to product/platform development managers.

Following the form of some other management models, for representation purposes "decision" is not considered a fifth stage, although there is still relevant operational effort involved. Noteworthy that the FSM considers here other "managerial insights" that could not take place in previous stages. For instance, strategies such as the nationalization of suppliers/subsystems and/or eventual commonalities among other products in development stage could be considered before issuing the final list of features to be included in the new vehicle specification, that is the main outcome of the methodology. Also, poor feature lists after the screening and scoring phases can send an important message about Gaps to be considered for new feature development in the global company; this can serve as relevant drivers for Roadmapping approaches as an alternative to guide such efforts.

\section{Discussion and implications}

Since the automobiles have medium-long development cycles in comparison to products of other industrial sectors, measuring the long-term performance of the FSM demands time and is dependent on other organizational variables among them, the division of labor among headquarters and subsidiaries (Chiesa, 1999; Matos et al., 2019; Proff, 2018). For the present case, some benefits and advantages were clear after the implementation of FSM in the routine of the Feature Planning area of the partner company as highlighted below. Noteworthy that these considerations come mainly from the several meeting notes, notes taken after informal conversations, e-mails and presentations made throughout the AR program, with increased intensity in the last 3 phases and that represent common thoughts and conclusions of the research team. The richer in-loco information provided by immersion in the real context, direct observation and collaboratively planned actions also helped to soften biases and distortions of individual people about what happened and about the major implications of the research for the organization (c.f. Eisenhardt \& Graebner, 2007).

FSM brings together central concepts of theoretical approaches of FEI to an operational basis, using logical sequence and tools adjusted to the constraints of a daily working. Considering Khurana \& Rosenthal (1998)'s classic model, FEI associates with product concept (phase zero) and product feasibility and planning (phase one). Company's strategy, market and technology concerns appear as inputs of the FEI model. Also, the FSM's graphic representation sheds light to elements like information gathering and decision-making approach, following Oliveira et al. (2011)'s proposed framework, aiming at a balance between discipline and flexibility in management. Lastly, FSM brings not just important elements from the business strategy to the Front End debate, but also uses well processed data from the back end (i.e. field problems and customer satisfaction) to nurture front end decisions (c.f. Katz, 2011; Markham \& Lee, 2013; Markham \& Mugge, 2015; Oliveira et al., 2016).

A computational tool for data handling and visualization reduces uncertainty and provides common language in FEI. The development of a computational tool allowed an easy sharing of the results and frequent data updating, which was fundamental to operate the FSM. As highlighted by Kim \& Wilemon (2002), since reliable information can systematically reduce uncertainty, an effective information system helps to continuously collect and evaluate fresh data. Furthermore, organizing data from multiple sources and formats in graphics and diagrams, together with the effort of grouping features into more general functions fostered the use of common language for people from different technical backgrounds, organizational functions and levels of analysis (as in Koen et al., 2001). This proved to be fundamental to the collaborative approach and to get to better managerial insights, which is also a central characteristic of wellestablished methods for technological forecasting (e.g. Roadmapping) and strategizing (Eppler \& Platts, 2009; Kim et al., 2018; Phaal et al., 2004).

FSM uses information and resources already available in the current organizational structure and fosters functional integration in FEI. The AR-program and the FSM enhanced the relationship between Feature Planning and Marketing/ Engineering areas making evident the benefits of a coordinated multifunctional work. As advocated by Péréa \& Von Zedtwitz (2018), task interdependence and more participative and communicative settings stimulate team interfaces and favor team integration. A good example in the case here approached is the market research process, that was significantly improved in order to meet FSM requirements for data collection and formatting (the academic team conducted regular weekly meetings with the market research analyst for about 2 months to improve market data collection and processing). This aspect is helpful to smooth the method implementation efforts.

This achievement also corroborates to Moenaert et al. (1995), who stated that uncertainty can be reduced by enhancing information exchange between marketing and R\&D-related functions. It was crucial for the development and success of FSM to integrate different perspectives (e.g. strategy, customer and competitors) in the same language 
(feature functions). In general, applying multidisciplinary teams is a common claim of many NPD works (Katz, 2011), but the challenges and complexity regarding the coordination of work and communication also increase substantially (Kim \& Wilemon, 2003; Koen et al., 2001). Even if information and resources can be considered "available", some functional integration must be fostered to go ahead in FFE. For instance, in the present case, the tasks concerning feature scoring (FSM step 4), which intensely counts on the expertise of NPD teams, revealed to be especially challenging for those features associated with Advanced Driver-Assistance Systems. According to the NPD analysts involved in research team, these are complex features that integrate many technologies from diverse knowledge fields. So, the assessment of these features in terms of company experience, cost, investment, and development time demanded a series of workshops among feature planning personnel and technical specialists that used to work in quasi-isolated settings. So, methods and tools like FSM can help taking the principles of collaboration and multidisciplinarity to practice.

The Feature Planning Team got more legitimacy in both the internal organization and in dealing with the external units. New functional groups associated with new systems and/or new technical domains often lack legitimation and representativeness in the organization (Meyer \& Rowan, 1977; Tolbert \& Zucker, 1999), which can jeopardize the efforts towards implementing a Feature-driven product development in the company.

FSM propelled a management process and the use of systematic coordination and communication the go across different activities and areas of the company, tying better the contribution of the Feature Planning team not just to the work of other internal organization functions but also in regard to other feature planning teams located in other units of the same corporation around the world. In what concerns this last perspective, the proposed tool is a potential lever to help dispersed teams in achieving cohesion (Péréa \& Von Zedtwitz, 2018). As the feature planning \& innovation manager once stated, FSM helps in a process where the local teams leave the passive role of knowledge user to take over the role of knowledge creator. This idea corroborates the tendency of international R\&D teams in playing increasingly important roles within the global process of technological innovation in multinational corporations (Chiesa, 1999).

Back to the internal organization, together with a formalized and organized way to analyze data and take decisions, the AR-program and the FSM (its main outcome) helped to increase the internal legitimacy of the feature planning team as well as of the deliverables it forwards to the other departments. This is crucial to consolidate new teams/processes associated with innovation in a large-sized company (c.f. Bagno et al., 2017; see Börjesson et al., 2014 for specific considerations in automotive companies; O'Connor et al., 2018).

FSM supports the organization in facing the challenges of an increasing number of functions and technologies in NPD. As the car is a complex and multifunctional product that is in the verge of many disruptions in terms of the increasing integration of new functions and technologies, a featuredriven approach is an emerging alternative to improve new product development practices (Lagerström et al., 2017; Maniak et al., 2014; Thölke et al., 2001). FSM seeks to take advantage of the expertise that NPD teams of diverse company's units build after developing product features (which is essential for reducing uncertainties) much more than it looks for seizing opportunities for parts sharing among different applications. In this way, the fact the platforms and/or modular designs are largely disseminated in the automotive industry helps in the extent that many different vehicles are comprised of systems with similar overall functions. However, the technical solutions of different vehicles will rarely be compatible with each other in the micro level. As Nobelius \& Sundgren (2002) argue in detail, transferring parts is a complex issue and involves many cross-boundaries and managerial concerns within the company. Notwithstanding, this aspect tends to foster the functional/system specialization of each NPD team involved, which is a strong assumption of the method.

FSM is well suited to a specific company's requirements, but its subjacent logic has potential contributions to other contexts. According to Cheng (2003), every method or tool is a product of its context in the extent that particular aims, orientations, desired outcomes and underlying assumptions strongly shape their development. Besides that, as stated in the previous session, AR intervention is particular and situational, but offers meaningful results to other contexts. FSM, in terms of its fundamental logic and stages, is weakly dependent on the firm's specificities, even though the operation of gathering, adapting and processing information was highly tied to the internal constraints, flows and rules.

Central elements as the categorization of features in elementary functions, nature and sources of data (e.g. strategy, field data); the aggregation of other company's expertise in feature scoring (e.g. feature cost, development time), and the forms to organize/show data and correlate them to managerial questions must all be adapted in some extension to apply FSM in other organizational contexts. The integration among these data sources in a single method is adherent to phased portfolio management approaches (such as Brook \& Pagnanelli, 2014; Terwiesch \& Ulrich, 2008) and is also conductive to the use of new digital technologies associated with the gathering, analyzing and taking advantage of big data (c.f. Markham \& Mugge, 2015). 
In designing FSM we observed important variables also raised by Freitas et al. (2019) when adapting a Roadmapping approach to complex organizational environments, viz, considering the consolidated technological paths of the organization as well as its particular strengths and weaknesses; and the sectoral contingencies needed to enhance managerial approaches. Thus, we recommend the same care when translating FSM to other settings. Lastly, not redundant to mention that despite FSM focuses just on the feature selection challenge it certainly generates relevant inputs to new feature development.

\section{Conclusion}

This study was based on a "how question", concerning the selection of features to include in a new vehicle specification, and considering a given list of features globally available in different units of a large automotive company. In the present context, a "feature" was defined as an "identifiable aspect of the total offering that a critical reference group perceives and evaluates as an 'extra' to a known standard among comparable products" (Thölke et al., 2001). The answer was given through the proposition of the FSM - Feature Selection Methodology, a 4-stage methodology built throughout a 7-month Action-Research program and that is based on a logical process of data gathering and analysis to reduce the inherent uncertainties of the decision-making at the Front End of Innovation. This study presented the main steps of the AR-program intervention and a detailed description of its results as well as some general implications for the partner company and the contemporary product development in automotive industry. The FSM intents to serve as a methodological reference for structuring and manage the FEI activities regarding feature selection and help establishing priorities for feature development for other applications and organizational contexts. In order to achieve this mission, it is important, therefore, to extrapolate and to test FSM in other organizations of the automotive sector with similar challenges, preferable located in markets where R\&D and NPD activities are intensely conducted.

\section{References}

Antonio, K. L., Richard, C. Y., \& Tang, E. (2009). The complementarity of internal integration and product modularity: an empirical study of their interaction effect on competitive capabilities. Journal of Engineering and Technology Management, 26(4), 305-326.

Backman, M., Börjesson, S., \& Setterberg, S. (2007). Working with concepts in the fuzzy front end: exploring the context for innovation for different types of concepts at Volvo Cars. $R \& D$ Management, 37(1), 17-28.
Bagno, R. B., Salerno, M. S., \& Dias, A. V. C. (2017). Innovation as a new organizational function: evidence and characterization from large industrial companies in Brazil. Production, 27, 27.

Balogun, J., Huff, A. S., \& Johnson, P. (2003). Three responses to the methodological challenges of studying strategizing. Journal of Management Studies, 40(1), 197-224.

Börjesson, S., Elmquist, M., \& Hooge, S. (2014). The challenges of innovation capability building: Learning from longitudinal studies of innovation efforts at Renault and Volvo Cars. Journal of Engineering and Technology Management, 31, 120-140.

Brook, J. W., \& Pagnanelli, F. (2014). Integrating sustainability into innovation project portfolio management: a strategic perspective. Journal of Engineering and Technology Management, 34, 46-62.

Chávez, A., \& Lara, A. (2016). Evolution of the complex nature of electrical vehicles. International Journal of Automotive Technology and Management, 16(4), 389-411.

Cheng, L. C. (2003). QFD in product development: methodological characteristics and a guide for intervention. International Journal of Quality \& Reliability Management, 20(1), 107-122.

Chiesa, V. (1999). Technology development control styles in multinational corporations: a case study. Journal of Engineering and Technology Management, 16(2), 191-206.

Cooper, R. G. (1988). Predevelopment activities determine new product success. Industrial Marketing Management, 17(3), 237-247.

Cooper, R. G., Edgett, S. J., \& Kleinschmidt, E. J. (1997). Portfolio management in new product development: Lessons from the leaders--I. Research Technology Management, 40(5), 16-28.

Coughlan, P., \& Coghlan, D. (2002). Action research for operations management. International Journal of Operations \& Production Management, 22(2), 220-240.

Donaldson, L. (2001). The contingency theory of organizations. Atlanta: Sage.

Eden, C., \& Huxham, C. (1996). Action research for management research. British Journal of Management, 7(1), 75-86.

Eisenhardt, K. M., \& Graebner, M. E. (2007). Theory building from cases: opportunities and challenges. Academy of Management Journal, 50(1), 25-32.

Elverum, C. W., \& Welo, T. (2015). On the use of directional and incremental prototyping in the development of high novelty products: two case studies in the automotive industry. Journal of Engineering and Technology Management, 38, 71-88. 
Eppler, M. J., \& Platts, K. W. (2009). Visual strategizing: the systematic use of visualization in the strategic-planning process. Long Range Planning, 42(1), 42-74.

Freitas, J. S., Bagno, R. B., Bertollo, C. M., Alves, T. M. A., Zani, C. L., Cheng, L. C., \& Gonçalves, C. A. (2019). Adapting the roadmapping approach to science-intensive organizations: lessons from a drug development program for neglected diseases. Journal of Engineering and Technology Management, 52, 3-15.

Högman, U., \& Johannesson, H. (2013). Applying stage-gate processes to technology development: experience from six hardware-oriented companies. Journal of Engineering and Technology Management, 30(3), 264-287.

Holahan, P. J., Sullivan, Z. Z., \& Markham, S. K. (2014). Product development as core competence: how formal product development practices differ for radical, more innovative, and incremental product innovations. Journal of Product Innovation Management, 31(2), 329-345.

Katz, G. (2011). Rethinking the product development funnel. Visions, 35(2), 24-31.

Khurana, A., \& Rosenthal, S. R. (1997). Integrating the fuzzy front end of new product development. MIT Sloan Management Review, 38(2), 103.

Khurana, A., \& Rosenthal, S. R. (1998). Towards holistic “front ends" in new product development. Journal of Product Innovation Management, 15(1), 57-74.

Kim, E., Beckman, S. L., \& Agogino, A. (2018). Design roadmapping in an uncertain world: implementing a customer-experience-focused strategy. California Management Review, 61(1), 43-70.

Kim, J., \& Wilemon, D. (2002). Focusing the fuzzy front-end in new product development. $R \& D$ Management, 32(4), 269-279.

Kim, J., \& Wilemon, D. (2003). Sources and assessment of complexity in NPD projects. $R \& D$ Management, 33(1), $15-30$

Koen, P., Ajamian, G., Burkart, R., Clamen, A., Davidson, J., D’Amore, R., Elkins, C., Herald, K., Incorvia, M., Johnson, A., Karol, R., Seibert, R., Slavejkov, A., \& Wagner, K. (2001). Providing clarity and a common language to the" fuzzy front end. Research Technology Management, 44(2), 46-55.

Lagerström, R., Addibpour, M., \& Heiser, F. (2017). Product feature prioritization using the Hidden Structure method: a practical case at Ericsson. In Portland International Conference on Management of Engineering and Technology (PICMET). Piscataway: IEEE.

Langner, B., \& Seidel, V. P. (2009). Collaborative concept development using supplier competitions: insights from the automotive industry. Journal of Engineering and Technology Management, 26(1-2), 1-14.

Maniak, R., Midler, C., Beaume, R., \& Von Pechmann, F. (2014). Featuring capability: how carmakers organize to deploy innovative features across products. Journal of Product Innovation Management, 31(1), 114-127.

Markham, S. K., \& Lee, H. (2013). Use of an innovation board to integrate the front end of innovation with formal NDP processes: a longitudinal study. Research Technology Management, 56(4), 37-44.

Markham, S. K., \& Mugge, P. C. (2015). Traversing the Valley of Death: a practical guide for corporate innovation leaders. Stephen K. Markham and Paul C. Mugge.

Matos, H. H. D., Dias, A. V. C., \& Bagno, R. B. (2019). Incremental and'radical'innovation in an emergent country automotive subsidiary: is there any organisational ambidexterity there? International Journal of Automotive Technology and Management, 19(3-4), 206-228.

Mendes, G. H. S., \& Oliveira, M. G. (2015). Bibliometric analysis of the front-end of innovation. In Portland International Conference on Management of Engineering and Technology (PICMET). Piscataway: IEEE.

Meyer, J. W., \& Rowan, B. (1977). Institutionalized organizations: formal structure as myth and ceremony. American Journal of Sociology, 83(2), 340-363.

Moenaert, R. K., De Meyer,A., Souder,W.E., \& Deschoolmeester, D. (1995). R\&D/marketing communication during the fuzzy front-end. IEEE Transactions on Engineering Management, 42(3), 243-258.

Morris, D., Madzudzo, G., \& Garcia-Perez, A. (2018). Cybersecurity and the auto industry: the growing challenges presented by connected cars. International Journal of Automotive Technology and Management, 18(2), 105-118.

Murphy, S. A., \& Kumar, V. (1997). The front end of new product development: a Canadian survey. $R \& D$ Management, 27(1), 5-15.

Nikitas, A., Njoya, E. T., \& Dani, S. (2019). Examining the myths of connected and autonomous vehicles: analysing the pathway to a driverless mobility paradigm. International Journal of Automotive Technology and Management, 19(12), 10-30

Nobelius, D., \& Sundgren, N. (2002). Managerial issues in parts sharing among product development projects: a case study. Journal of Engineering and Technology Management, 19(1), 59-73.

Nobelius, D., \& Trygg, L. (2002). Stop chasing the front end process: management of the early phases in product development projects. International Journal of Project Management, 20(5), 331-340. 
O’Connor, G. C., Corbett, A. C., \& Peters, L. S. (2018). Beyond the champion: institutionalizing innovation through people. Stanford: Stanford University Press.

Oliveira, M. G., Bagno, R. B., Mendes, G. H. S., Rozenfeld, H., \& Nascimento, P. T. (2016). The Front-Hub of Innovation: rethinking the front-end of the innovation process. In $R \& D$ Management Conference. Cambridge, UK: Center for Technology Management.

Oliveira, M. G., Phaal, R., Probert, D., Cunha, V. P., \& Rozenfeld, H. (2011). A starting point for addressing product innovativeness in the Fuzzy Front-End. International Journal of Technology Intelligence and Planning, 7(4), 309-326.

Péréa, C., \& Von Zedtwitz, M. (2018). Organic vs. mechanistic coordination in distributed New Product Development (NPD) teams. Journal of Engineering and Technology Management, 49, 4-21.

Persson, M., \& Åhlström, P. (2013). Product modularisation and organisational coordination. International Journal of Automotive Technology and Management, 13(1), 55-74.

Phaal, R., Farrukh, C. J., \& Probert, D. R. (2004). Technology roadmapping: a planning framework for evolution and revolution. Technological Forecasting and Social Change, $71(1-2), 5-26$.
Poskela, J., \& Martinsuo, M. (2009). Management control and strategic renewal in the front end of innovation. Journal of Product Innovation Management, 26(6), 671-684.

Proff, H. (2018). Heterogeneity of the steering of foreign subsidiaries in multinational automotive companies. International Journal of Automotive Technology and Management, 18(1), 29-45.

Reid, S. E., \& De Brentani, U. (2004). The fuzzy front end of new product development for discontinuous innovations: a theoretical model. Journal of Product Innovation Management, 21(3), 170-184.

Smith, P. G., \& Reinertsen, D. G. (1991). Developing products in half the time. New York: Van Nostrand Reinhold.

Terwiesch, C., \& Ulrich, K. (2008). Managing the opportunity portfolio. Research Technology Management, 51(5), 27-38.

Thölke, J. M., Hultinka, E. J., \& Robbenb, H. S. J. (2001). Launching new product features: a multiple case examination. Journal of Product Innovation Management, 18(1), 3-14.

Tolbert, P. S., \& Zucker, L. G. (1999). The institutionalization of institutional theory. In S. R. Clegg \& C. Hardy (Eds.), Studying organization: theory \& method (pp. 169-184). London: Sage. 